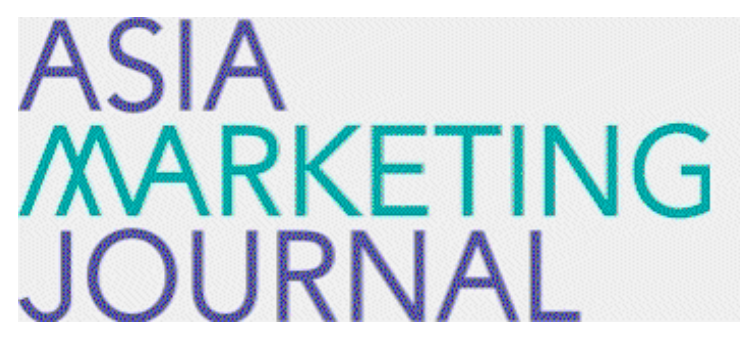

ASIA MARKETING JOURNAL

Volume 11 | Issue 4

Article 3

$1-30-2010$

\title{
기업의 사회적 책임이 기업 이미지에 미치는 영향
}

Seong Jin Kim

Jong Keun Kim

Follow this and additional works at: https://amj.kma.re.kr/journal

Part of the Marketing Commons

\section{Recommended Citation}

Kim, Seong Jin and Kim, Jong Keun (2010) "기업의 사회적 책입이 기업 이미지에 미치는 영향," Asia Marketing Journal: Vol. 11 : Iss. 4 , Article 3.

Available at: https://doi.org/10.53728/2765-6500.1244

This Article is brought to you for free and open access by Asia Marketing Journal. It has been accepted for inclusion in Asia Marketing Journal by an authorized editor of Asia Marketing Journal. 


\title{
기업의 사회적 책임이 기업 이미지에 미치는 영향 \\ - 차원별 파급효과와 메시지 유형을 중심으로 -*
}

\section{The Effect of Corporate Social Responsibility on Corporate Image: The Role of Spillover Effect and Negativity Effect based on CSR dimensions*}

\author{
김 성 진 $(\mathrm{Kim}, \text { Seongjin })^{* *}$ \\ 김 종 근(Kim, Jongkeun)***
}

기존의 많은 연구들은 기업의 사회적 책임(CSR)이 기업 성과와 높은 관련성이 있음을 보여 왔다. 하지만 대부분의 연구들이 기업의 사회적 책임을 단일 차원으로 보거나 구체적인 활동 중심으로 보 고 있다는 한계점을 가지고 있다. 본 연구는 이를 극복하기 위해 Schwartz and Carroll(2003)이 제시 한 $\mathrm{CSR}$ 의 세 가지 차원을 바탕으로, 각 차원별 메시지가 소비자들의 기업 이미지에 미치는 영향을 확인해 보고자 하였다. 연구 결과, 세 가지 기업의 사회적 책임 차원 중 법적 책임과 윤리적 책임에 대한 메시지는 파급효과가 일어나 다른 차원들에 대한 평가 결과에도 영향을 미치는 것으로 나타났 다. 또한, 긍정적 메시지일 때보다 부정적 메시지일 경우, 부정성 효과로 인한 파급효과가 더 커져, 법적 책임과 윤리적 책임에 대한 부정적인 메시지는 경제적 책임에 대한 메시지보다 기업 이미지를 더 크게 훼손시키는 것으로 나타났다.

핵심개념: 기업의 사회적 책임, 기업 이미지, 메시지 유형, 파급 효과, 부정성 효과

\section{I. 서 론}

최근 사회적으로 기업의 윤리 및 사회적 책임 에 관한 관심이 증가하면서 학계 및 기업에서는
기업의 사회적 책임(corporate social responsibility: 이하 (CSR)이 매우 중요한 이슈로 대두되고 있 다. 많은 기업들은 이미 자사의 긍정적인 기업 이미지를 형성하기 위한 마케팅 커뮤니케이션 도구로써 $\mathrm{CSR}$ 을 강조하는 광고를 활용하고 있

\footnotetext{
* 이 논문은 2009학년도 서울여자대학교 교내학술특별연구비의 지원을 받았음.

** 고려대학교 경영학과 박사과정(socialre@korea.ac.kr), 제1저자

*** 서울여자대학교 경영학과 전임강사(lion4184@swu.ac.kr), 교신저자
} 
으며, 학계에서도 $\mathrm{CSR}$ 과 관련된 다양한 연구들 이 진행되어 왔다.

경영학 관련 분야 연구들은 $\mathrm{CSR}$ 활동이 기 업 성과에 미치는 영향에 주로 초점을 맞추고, $\mathrm{CSR}$ 활동에 대한 메시지 혹은 정보가 기업이 나 제품 이미지, 태도, 구매 의도 등과 같은 기업 성과에 어떠한 영향을 미치는지에 대한 연구들을 진행해 왔다(Aupperle, Carroll, and Hatfield 1985; Becker-Olsen, Cudmore and Hill 2005; Brown and Dacin 1997; Cone and Roper 1997; Freeman 1991; Folkes and Kamins 1999; Klein and Dawar 2004; Sen and Bhattacharya 2001). 하지만 이들 연구들은 $\mathrm{CSR}$ 을 단일의 개념으로 보거나 구체적인 활동 을 기준으로 분류하고 있다는 한계점을 가지고 있다.

1953년 Bowen이 처음으로 CSR에 대한 학문 적 정의를 내린 이후, 지금에 이르기까지 많은 정의들이 제시되어 왔으나, 아직도 누구나가 동 의하는 공통의 정의는 존재하지 않고 있다. 그 럼에도 불구하고 $\mathrm{CSR}$ 개념과 관련된 대부분의 연구들은 $\mathrm{CSR}$ 을 하나의 단일 개념으로 보는 것이 아니라 여러 개의 하위 차원으로 구성된 개념으로 보고 있다(Carroll 1979, 1991; Maignan and Ferrell 2000; Schwartz and Carroll 2003; Wood 1991). 대표적인 연구로 Carroll(1979, 1991) 과 Schwartz and Carroll(2003)의 연구가 있다. Carroll(1979)은 CSR을 4가지 차원, 즉 경제적 책임, 법적 책임, 윤리적 책임, 그리고 자선적 책임 등으로 나누고 있으며, Schwartz and Carroll(2003)은 기존 Carroll이 제시한 차원 중 자선적 책임을 제외한 3 가지 차원, 즉 경제적 책임, 법적 책임, 그리고 윤리적 책임 등으로
$\mathrm{CSR}$ 을 구분하고 있다.

일반적으로, $\mathrm{CSR}$ 관련 메시지는 모든 차원에 대한 정보가 동시에 제공되기 보다는 여러 차 원들 중 하나 혹은 일부 차원에 대한 정보를 제공한다. 그렇다면 특정 차원에 대한 CSR 메 시지를 접한 소비자들은 어떤 과정을 통해 정 보를 받아들이는가? 예를 들어, 특정 기업이 법 을 잘 준수한다는 메시지를 접한 소비자들은 해당 메시지를 있는 그대로 받아들이기만 할 것인가? 아니면, 관련 메시지를 바탕으로 다른 정보를 유추할 것인가? Ahluwalia, Unnava, and Brunkrant(2001)의 연구에 의하면, 소비자 들은 브랜드의 속성에 관한 정보를 접하게 되 면, 그 정보를 있는 그대로 받아들이는 것이 아니라 해당 메시지 속에 언급되지는 않았으나 관련된 속성에 대해서도 추론을 하는데, 이러 한 현상을 파급 효과(spillover effect)라고 한다. 그러므로 $\mathrm{CSR}$ 차원들 중 하나 혹은 일부 차원 에 대한 메시지를 접한 소비자들은 파급효과로 인해 해당 차원에 대한 정보를 바탕으로 다른 차원들에 대해서도 추론을 할 가능성이 높다. 이러한 파급 효과는 $\mathrm{CSR}$ 차원에 대한 평가에 영향을 미치는 것에 그치는 것이 아니라 기업 이미지에 대한 평가에도 영향을 미칠 것이다. 파급 효과는 메시지 유형이 긍정적일 때보다, 부정적일 때 더 강하게 일어날 가능성이 높다. 이는 소비자들은 긍정적 메시지보다 부정적 메시지를 더 진단적이고 유용하게 받아들이는 부정성 효과(negativity effect) 때문이다(Fiske 1980; Herr, Kardes, and Kim1991).

따라서 본 연구의 목적은 $\mathrm{CSR}$ 차원별 메시 지를 소비자들이 처리하는 과정에서 파급효과 가 일어나는지 살펴보고, 메시지 유형(긍정적 
메시지 VS. 부정적 메시지)에 따라 기업 이미지 에 미치는 영향의 크기가 어떻게 달라지는지 살펴보고자 한다.

\section{II. 이론적 배경}

\section{1 기업의 사회적 책임 차원}

CSR에 대한 연구는 1953년 Bowen이 처음 학문적 정의를 내린 이후 지속적으로 진행되어 왔으며, 지금에 이르기까지 다양한 정의들이 제 시되고 있다. 그러나 아직까지도 $\mathrm{CSR}$ 에 대한 개념 정의가 명확하게 하나로 정리되지 못하고 있으며, 사회적 책임 활동과 관련된 용어들조차 기업책임(corporate responsibility or responsible business), 기업 시민 정신(corporate citizenship, $\mathrm{CC}$ ), 기업 지속 가능성(corporate sustainability), 기업 윤리(corporate ethics), 지속가능 기업가 정신(sustainable entrepreneurship) 등과 같이 다양하게 사용되고 있다. 이처럼 CSR이 다양한 개념과 형태로 발전되어 왔음에도 불구하고, $\mathrm{CSR}$ 개념과 관련된 연구들의 주요한 공통점은 $\mathrm{CSR}$ 을 단일 개념으로 보는 것이 아니라 여러 개의 하위 차원으로 구성된 개념으로 보고 있 다는 것이다(Carroll 1979, 1991; Davenport 2000; Maignan and Ferrell 2004; Prabu, Kline, and Dai 2005; Schwartz and Carroll 2003; Wood 1991). 이런 다양한 CSR 관련 개념을 정리하 고 설명하는데 있어 가장 많이 활용되는 것이 Carroll(1991)의 'CSR 피라미드(The Pyramid of (CSR)'이다. 이 모델 역시 CSR의 차원을 구
분하기에 완벽하지는 않지만, 가장 단순하면서 도 $\mathrm{CSR}$ 을 쉽게 이해할 수 있게 해주며, 실증적 으로 검증되어 온 모델이기 때문에 기존 연구 에서 가장 많이 활용되고 있다(Clarkson 1995; Ibrahim and Angelidis 1995; Pinkston \& Carroll 1994). Wood and Jones(1996)는 Carroll의 네 가지 영역에 대해 "CSR에 대해 연구하는 학자 들 사이에서 폭넓게 사용되는 대중적인 개념" 이라고 이야기하고 있으며, Schwartz and Carroll (2003) 역시 "Carroll의 CSR 개념을 바탕으로 한 네 가지 영역과 $\mathrm{CSR}$ 피라미드는 CSR관련 패 러다임을 이끌어 온 개념”이라고 언급하면서 매우 유용한 개념이라고 말하고 있다.

Carroll(1979)은 과거에 진행되어 온 다양한 $\mathrm{CSR}$ 개념들을 통합하기 위해 경제적, 법적, 윤 리적, 그리고 자선적 책임이라는 4가지 형태로 재분류하였다. 경제적 책임은 기업이 생산성 통 제나 고객 불평 관리 등과 같은 방법을 통해, 사회가 기대하는 제품이나 서비스를 생산하면 서 높은 수익성을 추구하는 것을 의미한다. 법 적 책임은 기업이 법의 체계 내에서 주어진 의 무들에 대해 사회가 기대하는 수준을 충족시키 는 것이다. 윤리적 책임은 기업이 도덕적으로 올바른 일들을 실행하는 것을 의미하며, 자선적 책임은 기업이 더 나은 사회를 만들기 위해 사 회가 기대하는 것들을 충족시키는 것으로 기부 나 기업의 자원봉사 등과 같은 것을 말한다. 그 리고 이러한 4 가지 책임 영역은 피라미드 형태 를 이루고 있다고 주장하였다(Carroll 1991).

이후 Schwartz and Carroll(2003)은 CSR 피 라미드에 대해 문제점을 제기하였다. 첫 번째, 피라미드형의 모양으로 인해, 상위에 있는 자선 적 책임이 가장 하위에 있는 경제적 책임보다 
더 중요한 것처럼 잘못된 해석을 한다는 것이 다. 두 번째, 자선적 책임은 기업의 경제적 성 과와 관련이 있을 뿐만 아니라 윤리적 책임과 는 실질적으로 구분하기가 거의 불가능하다고 주장한다. 이러한 이유로 Schwartz and Carroll (2003)은 자선적 책임을 제외한 나머지 세 가 지 차원으로 $\mathrm{CSR}$ 을 나누고 있다. 그들의 연구 에 의하면, 경제적 책임은 기업이 생산성 통제 나 고객 불평 관리 등과 같은 방법을 통해, 사 회가 기대하는 제품이나 서비스를 생산하면서 높은 수익성을 추구하는 것으로서, 수익의 극대 화나 주주 가치의 극대화라는 형태로 나타난다. 법적 책임은 사회에 의해 지시되고 기대되어지 는 법적 기대에 대한 기업의 책임으로, 법에 대 한 순응, 법적 소송의 회피, 법보다 앞선 활동 등으로 나타난다. 마지막으로 윤리적 책임은 일 반 대중과 관련 이해관계자들에 의해 기대되는 것으로서, 전통적 기준, 결과론적 기준, 의무론 적 기준으로 나누어 볼 수 있다. 본 연구에서 는 CSR 차원을 분류함에 있어 Schwartz and
Carroll(2003)의 주장을 받아들여 CSR을 세 가 지 차원(경제적 책임, 법적 책임, 윤리적 책임) 으로 나누어 연구를 진행하고자 한다.

\section{2 기업 이미지}

$\mathrm{CSR}$ 활동의 결과로 많이 사용되는 변수들 중의 하나가 기업 이미지이다. 기업 이미지란 기업에 대해 대중의 마음속에 형성되어 있는 종합적인 인상이다(Barich and Kotler 1991; Dichter 1985; Kotler 1982). 이것은 기업명이나 다양한 제품이나 서비스 등과 같은 기업의 다 양한 속성들과 관련되어 있는데, 이러한 속성과 관련하여 사람들은 저마다 기업에 대해 다른 형태의 경험을 가지고 있기 때문에 기업 이미지 또한 다르게 형성된다. Fombrun and Shanley (1990) 등에 의하면, 기업의 이미지는 다양한 이해 관계자 그룹에게 신호를 보내는 기능을 하는데, 이러한 신호는 기업에 대해 직접적으로 관찰할 수 없는 부분들에 대한 다양한 정보들

\section{〈그림 1〉Carroll(1991)의 CSR 피라미드}

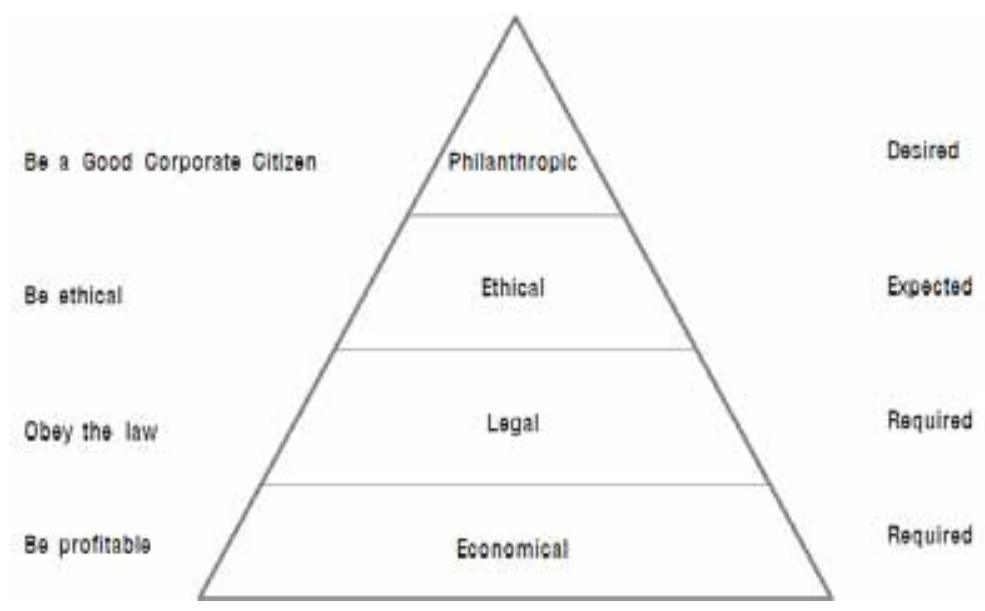


을 제공하기 때문에 경쟁 시장에서 중요한 기 능을 한다. 다양한 이해관계자들은 자신들의 필 요와 욕구를 제공하거나 충족시키는데 해당 기 업이 효과적인지 판단하는데 필요한 다양한 단 서나 신호를 선택적으로 처리할 때, 기업 이미 지가 중요한 작용을 한다. 그러므로 기업은 이 해관계자 그룹 중 하나인 소비자들이 자신의 필요와 욕구를 충족시키기 위해 필요한 선택을 할 때, 자사에 대한 판단 요소로 기업 이미지를 활용하기 때문에 이를 잘 관리할 필요가 있다.

이러한 기업 이미지를 향상시키고 유지하는데 CSR은 유용한 도구이다. Freeman(1991) 과 Brown and Dacin(1997)에 의하면, 지속적인 사회적 책 임 활동은 장기적으로 기업에 대한 긍정적인 이미지를 제고시켜 줄 수 있는 강력한 커뮤니 케이션 도구의 역할을 수행한다. CSR 활동의 효과는 단순히 소비자들로 하여금 긍정적인 태 도나 이미지를 형성하는데서 그치지 않고, 소비 자들이 기업에 대한 부정적인 정보에 노출되더 라도 CSR로 인해 형성된 긍정적인 태도로 인 해 기업에 대한 긍정적인 이미지를 유지하는데 도움이 된다(Klein and Dawar 2004). Till and Nowak(2000)은 한발 더 나아가 CSR 활동을 통해 향상된 기업 이미지는 구매 의도에 직접 적인 영향을 미치고 있음을 보여주었다. 그러므 로 기업이 강력하고 긍정적인 기업 이미지를 형성하기 위한 도구로써 $\mathrm{CSR}$ 은 적절한 도구임 을 알 수 있다.

\section{3 가설 설정}

기존의 많은 연구들은 $\mathrm{CSR}$ 활동이 소비자들 로 하여금 긍정적인 기업 이미지를 형성하고
유지하는데 유용한 마케팅 도구임을 보여주고 있다(Becker-Olsen, Cudmore and Hill 2005; Brown and Dacin 1997; Cone and Roper 1997; Freeman 1991; Folkes and Kamins 1999; Klein and Dawar 2004; Sen and Bhattacharya 2001). 하지만 이들 연구 대부분은 $\mathrm{CSR}$ 을 단일 차원 으로 보고 있다는 한계를 가지고 있다. 앞서 여 러 연구들에서 제시한 것처럼 $\mathrm{CSR}$ 은 단일 차 원이 아니라 여러 하부 차원으로 구성된 개념 이다(Carroll 1991; Schwartz and Carroll 2003; Wood 1991; Maignan and Ferrell 2000). 그러 므로 $\mathrm{CSR}$ 활동이 기업 이미지에 미치는 영향 력을 좀 더 정확히 보기 위해서는 $\mathrm{CSR}$ 차원별 로 기업 이미지에 미치는 영향력을 살펴보아야 할 것이다.

그렇다면 $\mathrm{CSR}$ 을 단일 차원이 아니라 여러 하위 차원으로 나누고, 각 차원별 활동에 대한 메시지를 소비자들에게 제시하면, 소비자들은 어떠한 반응을 보일까? Fishbein and Ajzen (1981)에 의하면, 커뮤니케이션은 메시지 속에 언급되지 않은 속성에 관한 신념에도 영향을 미칠 수 있기 때문에, 마케팅 커뮤니케이션의 효과를 완전히 이해하기 위해서는 파급효과에 대한 연구가 필요함을 주장하였다. 파급 효과 (spillover effect)란 메시지를 통해 제공된 정보 가 메시지에서 언급하지 않은 속성에 대한 신 념을 변화시키는 것을 의미한다(Ahluwalia, Unnava, and Burnkrant 2001). 이러한 파급 효과는 CSR 차원들 간에도 발생할 가능성이 있다. 예를 들 어, 법을 잘 지키는 기업이라는 메시지를 접한 소비자들은 해당 기업이 윤리적 책임도 잘 준 수할 것이라고 추론한다거나, 법을 잘 지키느라 경제적 성과는 그리 좋지 못해 경제적 책임은 
다하지 못하고 있다고 추측할 수 있다. 이는 세 가지 차원들 중 한 가지 차원에 대한 메시지를 접하더라도, 파급효과로 인해 다른 차원들에 대 한 추론을 하는 현상이 발생함을 의미한다. 이 러한 현상을 확인하기 위해, 다음과 같이 가설 을 설정하였다.

가설 1: CSR 차원 중 하나의 차원에 대한 메시지는 파급효과로 인해 다른 차 원에 대한 소비자 평가에도 영향을 미칠 것이다.

Ahluwalia et al.(2001)의 연구에 의하면, 소 비자들이 브랜드에 익숙하지 않으면서 부정적 인 정보가 제공될 때 메시지에 직접적으로 제 시되지 않고 있는 속성에 대해서도 파급 효과 가 일어나지만, 긍정적인 정보일 때는 일어나지 않는 것을 발견하였다. 이는 소비자들이 긍정적 인 정보보다 부정적인 정보에 대해 더 크게 반 응하기 때문이다. Skowronski and Carlston(1989) 은 비대칭 효과(asymmetric effect)를 통해 사 람을 설득하기 위해 제공된 긍정적 정보와 부 정적 정보는 그 영향력이 다르게 나타난다고 주장하였다. Herr, Kardes, and $\operatorname{Kim}(1991)$ 과 Homer and Batra(1994)의 연구 역시, 잘 알려 지지 않은 사람이나 브랜드에 대한 종합적인 평가일 경우, 긍정적인 정보보다는 부정적인 정보가 더 큰 영향을 미치는 것으로 나타났다. 이처럼 긍정적인 정보보다 부정적인 정보를 더 욱 진단적으로 인식하는 현상을 부정성 효과 (negativity effect)라고 한다(Maheswaran and Meyers-Levy 1990; Skowranski and Carlston 1989). Fiske(1980)는 부정성 효과가 나타나는
이유를 부정적 정보에 대한 지각된 신기함 (perceived novelty) 때문이라고 주장한다. 즉, 부정적 정보의 특징이 더 큰 주의를 끌기 때문 에, 평가에 더 큰 영향을 미친다는 것이다. 반 면, Feldman and Lynch(1988)는 부정성 효과 가 나타나는 이유를 부정적 정보의 진단성 때 문이라고 말한다. 진단성이란 의사 결정에 있어 서 정보의 지각된 관련성 혹은 유용성을 말한 다. 만일 소비자들이 제품에 대한 부정적인 정 보를 듣는다면, 소비자들은 해당 제품을 저품질 군으로 묶을 수 있다. 하지만 긍정적이거나 중 립적인 정보를 접한 소비자는 그것들을 하나의 제품군으로 묶지 않는다. 왜냐하면, 긍정적이거 나 중립적인 정보들은 고품질이건, 중간 품질이 건, 혹은 저품질이건, 모든 종류의 제품들에 모 두 포함되어 있기 때문이다. 즉, 긍정적이거나 중립적인 기능은 모든 제품에 다 해당하지만, 부정적인 기능은 나쁜 제품에게만 해당하기 때 문이다(Herr, Kardes, and Kim 1991).

그러므로 파급 효과는 Fiske(1980)나 Herr, Kardes, and $\operatorname{Kim}(1991)$ 이 주장한 것처럼, 부정 성 효과가 함께 발생할 때 더 강하게 일어날 것으로 예상할 수 있다. 이는 소비자들에게 있 어 $\mathrm{CSR}$ 에 대한 부정적인 정보는 긍정적인 정 보보다 소비자들의 주의를 더 잘 끌 뿐만 아니 라, 부정적인 정보 자체가 소비자들이 기업 이 미지를 형성하는데 있어서 더 진단적이고 유용 하기 때문이다. 즉, $\mathrm{CSR}$ 차원 중 하나의 차원 에 대한 부정적 메시지를 접한 소비자들은 부 정성 효과로 인해 긍정적 메시지보다 파급효과 는 더 커질 것이고, 이로 인해 기업 이미지에 미치는 영향도 더 커질 것으로 예상할 수 있다. 그러므로 다음과 같이 가설을 설정하였다. 
가설 2: CSR 차원별 메시지의 파급효과는 긍정적인 메시지보다 부정적인 메 시지에서 더 크게 일어나 소비자들 의 기업 이미지에 더 큰 영향을 미 칠 것이다.

\section{III. 실험 설계}

\section{1 실험 자극물의 선정 및 조작화 확인}

본 연구에서는 CSR 차원별(경제적 책임 vs. 법적 책임 vs. 윤리적 책임) 메시지 유형(긍정 적 메시지 vs. 부정적 메시지)이 기업 이미지에 미치는 영향을 알아보고자 집단 간 요인 설계 (between-subject factorial design)를 하였다. 본 실험에 앞서, 실험 자극물이 제대로 만들어 졌는지를 평가하기 위해 사전 조사가 이루어 졌다. 사전 조사는 수도권 대학생 64 명을 대상 으로 이루어졌으며, 실험을 위해 '한국 건설'이 라는 가상의 회사를 활용하였다. CSR 차원은 Schwartz and Carroll(2003)의 분류를 따라 3가 지 차원(경제적 책임 vs. 법적 책임 vs. 윤리적 책임)으로 나누었고, 각 차원별로 긍정적인 메 시지와 부정적인 메시지를 담은 가상의 신문
기사를 만들어 각 집단에게 노출시킨 후, 각각 의 기사가 CSR 차원과 얼마나 관련성이 있는 지를 리커트 7점 척도를 통해 평가하게 하였다 (1점: 전혀 그렇지 않다, 7점: 매우 그렇다). 이렇게 얻어진 결과를 바탕으로 ANOVA를 통 해 집단 간 차이를 분석하였다. 다음의 〈표 1〉 은 각 집단별 평균값을 보여준다. 경제적 책임 에 대한 기사를 접한 피실험자들은 해당 기사 가 법적/윤리적 책임보다 경제적 책임과 높은 관련성이 있다고 응답하였으며, 이는 통계적으 로 차이를 보이는 것으로 나타났다 $(\mathrm{F}=15.196$, $\mathrm{p}=.000)$. 법적 책임 $(\mathrm{F}=11.444, \mathrm{p}=.000)$ 과 윤 리적 책임 $(\mathrm{F}=19.368, \mathrm{p}=.000)$ 에 대한 검증 결 과 역시 경제적 책임과 마찬가지로, 해당 차원 과는 높은 관련성을 보이지만 다른 차원과는 관련성이 낮은 것으로 나타났으며, 그 차이는 통계적으로 유의한 수준으로 나타나 CSR 차원 에 대한 조작화가 제대로 이루어졌음을 알 수 있었다. 또한 각 차원별 메시지 유형의 강도 차 이를 조절하기 위해 각 차원별 메시지를 긍정 적일 때와 부정적일 때로 나누어 차이를 보이 는지 분석을 실시하였다. 먼저 3 가지 차원별 긍 정적인 메시지들끼리 비교한 결과 3 가지 차원 별 메시지 모두 통계적으로 유의한 차이를 보 이지 않아 메시지 강도가 동일함을 알 수 있다 $(\mathrm{F}=1.122, \mathrm{p}=.339)$. 부정적 메시지 유형에서도

〈표 1〉사전 실험 집단별 평균값

\begin{tabular}{|c|c|c|c|c|c|c|}
\hline \multirow{3}{*}{$(\mathrm{N}=64$ 명 $)$} & \multicolumn{2}{|c|}{ 경제적 책임 } & \multicolumn{2}{|c|}{ 법적 책임 } & \multicolumn{2}{c|}{ 윤리적 책임 } \\
\hline & $\begin{array}{c}\text { 긍정적 } \\
\text { 메시지 } \\
(\text { 집단 1) }\end{array}$ & $\begin{array}{c}\text { 부정적 } \\
\text { 메시지 } \\
\text { (집단 2) }\end{array}$ & $\begin{array}{c}\text { 긍정적 } \\
\text { 메시지 } \\
\text { (집단 3) }\end{array}$ & $\begin{array}{c}\text { 부정적 } \\
\text { 메시지 } \\
\text { (집단 4) }\end{array}$ & $\begin{array}{c}\text { 긍정적 } \\
\text { 메시지 } \\
\text { (집단 5) }\end{array}$ & $\begin{array}{c}\text { 부정적 } \\
\text { 메시지 } \\
(\text { 집단 6) }\end{array}$ \\
\cline { 2 - 7 } & 6.00 & 6.18 & 5.10 & 6.30 & 5.82 & 6.6 \\
\hline
\end{tabular}


집단 간의 평균값이 약간씩은 차이가 있지만 역시 유의한 차이를 보이지 않아 메시지 강도 가 제대로 조작화 되었음을 알 수 있다 $(\mathrm{F}=$ 1.718, $\mathrm{p}=.197$ ).

\section{2 표본의 선정 및 실험 집단의 구성}

본 실험에는 수도권 지역 대학의 학부생 206 명이 참여하였다. 이중 불성실 응답자 5 명의 자 료를 제외한 나머지 201명의 자료가 분석에 사 용되었다. 실험 집단은 $\mathrm{CSR}$ 차원(경제적 책임 Vs. 법적 책임 Vs. 윤리적 책임) $\mathrm{X}$ 메시지 유형 (긍정적 메시지 Vs. 부정적 메시지)의 총 6 개 집단으로 구분되었다.

\section{3 실험 절차 및 자료 수집}

실험은 수도권 지역 대학생을 대상으로 약 30 여분에 걸쳐 진행되었으며, 실험에 들어가기 전, 연구자는 피실험자들에게 실험과 관련된 주 의 사항을 간략히 설명하였다. 이어 피실험자들 에게 CSR 차원(경제적 책임 VS. 법적 책임 VS. 윤리적 책임)과 메시지 유형(긍정적 메시지 VS. 부정적 메시지)에 따라 각각 다르게 제작된 6 가지 유형의 시나리오들 중 하나가 제시되었고, 기사를 본 후 '한국 건설'의 $\mathrm{CSR}$ 차원별 항목 과 기업 이미지에 대한 평가를 하도록 하였다.

\section{4 조작적 정의}

\subsubsection{CSR 차원별 성과 평가}

$\mathrm{CSR}$ 의 3가지 차원에 대한 성과 평가를 위해 Maignan(2001)의 연구에서 활용된 측정 항목을 본 연구에 맞게 수정하여 사용하였다. Maignan (2001)은 소비자들을 대상으로 CSR의 하위 차 원들을 측정하기 위해 Carroll(1979, 1991)이 제 시한 4 가지 차원별로 4 개씩 총 16 개 항목을 개 발하였고, 미국, 프랑스, 그리고 독일에서 타당 성과 신뢰성을 검증하였다. 이 척도를 기반으 로, 경제적 책임은 이윤 극대화, 생산비 통제, 장기적 계획 수립, 지속적인 경제적 성과 향상 등 4 개 항목으로 측정되었으며, 법적 책임은 종 업원 권리 보장, 계약 이행, 성과를 위한 법의 남용, 준법 등 4 개 항목으로 구성되어 있다. 마 지막으로 윤리적 책임은 윤리적 책임에 대한 관심, 윤리적 원칙의 존중 및 보장, 내부 윤리 원칙, 그리고 윤리적 기준 준수 등 4 가지 항목 으로 측정되었으며, 각 항목에 대해 얼마나 중 요하게 생각하는지를 물었다. 각 항목(1: 전혀 그렇지 않다, 7: 매우 그렇다)에는 리커트 7점 척도가 사용되었다.

〈표 2〉본 실험 집단의 구성

\begin{tabular}{|c|c|c|c|}
\hline 표 빕단불 & 경제적 책임 & 법적 책임 & 윤리적 책임 \\
\hline 긍정적 메시지 & 34 & 34 & 32 \\
\hline 부정적 메시지 & 34 & 35 & 32 \\
\hline
\end{tabular}




\section{4 .2 기업 이미지}

Barich and Kotler(1991)는 기업 이미지를 기 업에 대해 대중의 마음속에 형성되어 있는 종 합적인 인상으로 정의 내리고 있다. 이러한 기 존의 정의를 바탕으로, 본 연구에서는 기업 이 미지를 측정하기 위해 Winter(1986)가 개발한 13 개의 항목을 사용하였다. Winter(1986)는 기 업 이미지를 기업 행동 요인, 사회적 행동 요 인, 그리고 기업 공헌 요인 등 3 가지 영역으로 나누고 있다. 기업 행동 요인은 수익성, 제품 가격, 서비스 품질, 좋은 회사가 되기 위한 노 력, 주식 투자 대상, 제품 품질 등의 6가지 항 목으로 구성되어 있으며, 사회적 행동 요인은 환경보호, 공공사업, 정직한 보고, 그리고 세금 납부 등의 4 가지 항목으로 구성되어 있으며, 기 업 공헌 요인은 사회적 평판, 문화적 공헌, 그 리고 사회 복지 공헌 등의 3가지 항목으로 구 성되어 있다. 이들 항목을 측정하기 위해 리커 트 7점 척도가 사용되었다(1: 전혀 그렇지 않 다, 7: 매우 그렇다).

\section{5 신뢰성 및 타당성 검증}

Anderson and Gerging(1988)이 제시한 것 처럼, CSR 성과 및 기업이미지에 대한 항목 들을 대상으로 단일차원성(unidimensionality), 집중 타당성(convergent validity), 판별 타당성 (discriminant validity) 그리고 신뢰성(reliability) 을 확인하기 위해 확증적 요인분석과 신뢰도 분석을 실시하였다. 신뢰도 분석 결과 기업 이 미지 중 기업 공헌과 관련된 변수 중 하나 (hcol)가 신뢰도를 심각하게 저해하는 것으로
나타나 추후 분석에서 제외되었다 $(a=0.834->$ $a=0.584)$. 그 외의 항목들은 0.7 을 넘는 것으 로 나타나 측정 도구로서의 신뢰성을 갖고 있 는 것으로 나타났다(Nunnally 1978). 또한 CSR 성과 및 기업이미지에 대한 항목들을 대상으로 추가적인 신뢰성 검증을 위해서 LISREL 8.30 패키지를 활용하여 $\mathrm{CR}$ 과 $\mathrm{AVE}$ 를 산출하였다. Fornell and Larker(1981)가 제시한 방식으로 산출한 $\mathrm{CR}$ 은〈표 3〉과〈표 4>에서와 같이 모 든 변수에서 Fornell and Larker(1981)가 제시 한 기준인 0.7 보다 모두 높음을 알 수 있으며, AVE측면에서 모든 변수들에 대해서 Fornell and Larker(1981)가 제시한 기준인 0.5보다 높 은 값을 보이고 있다. CSR 성과에 대한 타당도 분석을 위해 측정모델을 구성하여 반복적인 확 증적 요인분석을 실시하였으며, 요인분석 도중 경제적 책임성과 항목 중 한 항목(hec1)이 다 른 요인과 관련성이 높게 나타나 제거하였다. 측정모델의 적합도는 대체로 만족할 수준을 보 이고 있으며 $\left(\mathrm{x}^{2}\right.$ (d.f. $\left.=37\right)=99.575(\mathrm{p}=0.000)$, RMSEA $=.0520, \mathrm{CFI}=0.889, \mathrm{NNFI}=0.835$, $\mathrm{GFI}=0.947, \mathrm{AGFI}=0.905)$, 개별 측정변수 들에 대한 요인적재량 역시 통계적으로 유의미 한 값을 보임에 따라 $\mathrm{CSR}$ 성과변수들에 대한 타당성은 적합하다고 판단할 수 있다. 추가적으 로 집중 타당성을 검증하기 위해 다중 자승 계 수 값(the squared multiple coefficient value) 을 확인한 결과, 모든 항목들은 각각의 요인별 로 잘 분류되어 집중 타당성 역시 문제가 없는 것으로 나타났다(the lowest $t$-value>6.36).

다음으로 3 가지 하위 차원으로 구성된 기업 이미지에 대한 타당도 분석을 위해 2 단계 확증 적 요인분석을 반복적으로 실시하였다. 요인분 
〈표 3〉 CSR 성과에 대한 확증적 요인분석 및 신뢰도 분석 결과

\begin{tabular}{|c|c|c|c|c|c|c|c|c|c|c|c|}
\hline & \multicolumn{3}{|c|}{$\begin{array}{c}\text { 경제적 책임성과 } \\
(\mathrm{a}=0.737)\end{array}$} & \multicolumn{3}{c|}{$\begin{array}{c}\text { 법적 책임 성과 } \\
(\mathrm{a}=0.852)\end{array}$} & \multicolumn{3}{c|}{ 윤리적 책임성과 } \\
$(\mathrm{a}=0.993)$
\end{tabular}

〈표 4〉기업 이미지에 대한 2단계 요인분석 및 신뢰도 분석 결과

\begin{tabular}{|c|c|c|c|c|c|c|c|c|c|c|c|}
\hline construct & \multicolumn{5}{|c|}{ 기업 행동 $(a=0.844)$} & \multicolumn{4}{|c|}{ 사회적 행동 $(a=0.816)$} & \multicolumn{2}{|c|}{$\begin{array}{l}\text { 기업 공헌 } \\
(a=0.834)\end{array}$} \\
\hline indicator & hce2 & hce3 & hce4 & hce5 & hce6 & hen1 & hen2 & hen3 & hen4 & hco2 & hco3 \\
\hline estimate & 0.52 & 0.74 & 0.72 & 0.73 & 0.92 & 0.82 & 0.65 & 0.77 & 0.70 & 0.86 & 0.85 \\
\hline t-value & - & 7.96 & 6.72 & 6.88 & 7.79 & - & 9.69 & 10.85 & 9.87 & - & 13.71 \\
\hline $\mathrm{SMC}$ & 0.469 & 0.548 & 0.525 & 0.532 & 0.842 & 0.670 & 0.516 & 0.598 & 0.583 & 0.746 & 0.720 \\
\hline AVE & \multicolumn{5}{|c|}{0.558} & \multicolumn{4}{|c|}{0.541} & \multicolumn{2}{|c|}{0.733} \\
\hline $\mathrm{CR}$ & \multicolumn{5}{|c|}{0.857} & \multicolumn{4}{|c|}{0.823} & \multicolumn{2}{|c|}{0.846} \\
\hline
\end{tabular}

\begin{tabular}{|c|c|c|c|}
\hline construct & \multicolumn{3}{|c|}{ 기업이미지 $(\mathrm{a}=0.854)$} \\
\hline indicator & 기업 행동 & 사회적 행동 & 기업 공헌 \\
\hline estimate & 0.90 & 0.98 & 0.92 \\
\hline t-value & 7.11 & 12.82 & 0.955 \\
\hline SMC & 0.802 & 0.973 & \\
\hline AVE & \multicolumn{3}{|c|}{0.804} \\
\hline CR & \multicolumn{3}{|c|}{0.925} \\
\hline
\end{tabular}

석 도중 기업 행동 항목 중 하나(hcel)가 다른 요인과 관련성이 높게 나타나 제거되었다.

2단계 요인 분석 결과 모든 적합도 지수에서 대체로 유의미한 수준을 보이고 있으며 $\left(\mathrm{X}^{2}\right.$ (d.f. $=$ $37)=81.02(\mathrm{p}=0.0004)$, RMSEA $=.0571, \mathrm{CFI}$ $=0.915, \mathrm{NNFI}=0.874, \mathrm{GFI}=0.952$, AGFI
$=0.914)$, 개별 측정변수들에 대한 요인적재량 역시 통계적으로 유의미한 값을 보임에 따라 기업 이미지 변수들에 대한 타당성은 적합하다 고 판단할 수 있다. $\mathrm{CSR}$ 성과와 마찬가지로 추 가적인 집중 타당성을 검증하기 위해 다중 자 승 계수(the squared multiple coefficient)를 확 
인한 결과, 모든 항목들이 각각의 관련 항목들 과 잘 묶여 집중 타당성이 있는 것으로 나타났 다(the lowest $\mathrm{t}$-value > 6.72).

\section{6 가설 검증}

가설을 검증하기 위해, 우선 긍정적 메시지 를 접한 집단과 부정적 메시지를 접한 집단으 로 나누었다. 그리고 Ahluwalia, Unnava, and Burnkrant(2001)의 연구와 유사하게, 각 집단 별로 메시지와 관련된 CSR 차원의 성과 평가 결과와 관련이 없는 차원의 성과 평가 결과를 비교함으로 파급효과가 일어났는지 확인하였다. 다음으로 Janakiraman, Meyer, and Morales
(2006)가 가격 관련 정보에 따른 소비자의 구 매량 변화를 통해 파급효과를 간접적으로 분석 한 것처럼, 본 연구에서도 각 집단별 기업 이 미지의 차이 분석을 통해 $\operatorname{CSR}$ 차원과 메시지 유형별 파급 효과의 강도를 간접적으로 확인하 였다.

우선 긍정적 메시지를 접한 집단에서의 파급 효과를 확인해 보았다. 다음의〈표 5 〉는 분석 결과를 보여준다. 먼저 경제적 책임에 대한 긍정적인 메시지를 접한 집단은 경제적 책임 (5.1765)>법적 책임(4.3603)>윤리적 책임(3.9265) 순으로 높은 평가를 내렸으며, 법적 책임에 대 한 긍정적인 메시지를 접한 집단은 윤리적 책임 (5.0368) $=$ 법적 책임(4.9485)>경제적 책임(4.4338)

〈표 5〉 긍정적 메시지 효과 분석

\begin{tabular}{|c|c|c|c|c|c|}
\hline 기사 유형 유형별 평가 & $\begin{array}{l}\text { 경제적 책임 } \\
\text { 성과 }\end{array}$ & $\begin{array}{l}\text { 법적 책임 } \\
\text { 성과 }\end{array}$ & $\begin{array}{l}\text { 윤리적 책임 } \\
\text { 성과 }\end{array}$ & $\begin{array}{l}\text { 기업 } \\
\text { 이미지 }\end{array}$ & $\begin{array}{l}\text { 기업 이미지 } \\
\text { 차이 검증 }\end{array}$ \\
\hline 경제적 책임 $(+)$ & 5.1765 & 4.3603 & 3.9265 & 4.3302 & \multirow{3}{*}{$\begin{aligned} \mathrm{F} & =2.904 \\
(\mathrm{p} & =0.060)\end{aligned}$} \\
\hline 법적 책임(+) & 4.4338 & 4.9485 & 5.0368 & 4.8342 & \\
\hline 윤리적 책임 $(+)$ & 4.1406 & 4.9453 & 5.2813 & 4.7179 & \\
\hline
\end{tabular}

〈그림 2〉 CSR 차원별 긍정적 메시지의 효과

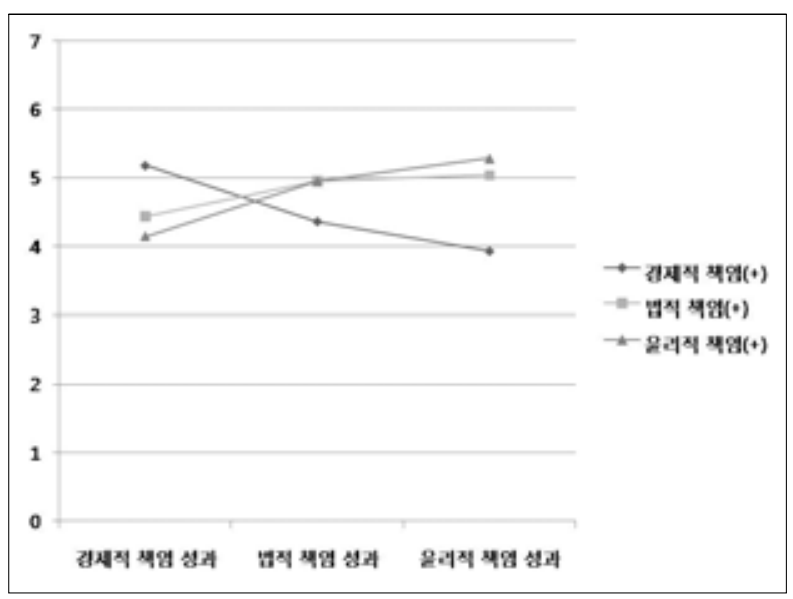


의 순으로 나타났으며, 윤리적 책임에 대한 긍정적인 메시지를 접한 집단은 윤리적 책임 (5.2813) =법적 책임(4.9453)>경제적 책임(4.1406) 의 순서로 높게 평가한 것으로 나타났다. 분석 결과, 법적 책임과 윤리적 책임 사이에는 파급 효과가 일어났지만, 경제적 책임에 대한 메시지 를 접한 집단에서는 파급효과가 나타나지 않았 다. 이는 경제적 책임에 대한 긍정적인 정보를 접한 집단의 경우 다른 부분보다 경제적 책임 에 대한 평가가 특히 높게 나타나 파급 효과가 크게 일어난 것으로 보기 어려운 반면, 법적 책 임과 윤리적 책임에 대한 긍정적인 정보는 다 른 부분에 대한 평가도 높게 나타나 파급 효과 가 일어나고 있음을 알 수 있다.
이러한 파급 효과가 기업 이미지에 어떠한 영 향을 미쳤는지 알아보기 위해 분석을 실시하였 다. 그 결과 세 집단 간에 차이는 유의하지 않 는 것으로 나타났다 $(\mathrm{F}=2.904, \mathrm{p}=.060)$. 즉, 긍 정적 메시지로 인한 파급 효과는 기업 이미지 평가 결과에 차이를 줄 만큼 크게 일어나지 않 는 것으로 나타났다.

다음으로 부정적 메시지를 접한 집단 속에서 의 파급 효과를 알아보기 위해 차원별 성과 평 가 결과를 집단별로 비교하였다. 다음의〈표 6〉 은 분석 결과를 보여준다.

경제적 책임에 대한 부정적 정보를 접한 집단 의 경우, 경제적 책임(3.6176)<법적 책임(4.3676) $=$ 윤리적 책임(4.5515) 순으로, 법적 책임에 대

〈표 6〉부정적 메시지 효과 분석

\begin{tabular}{|c|c|c|c|c|c|}
\hline 기사 유형 유형별 평가 & $\begin{array}{l}\text { 경제적 책임 } \\
\text { 성과 }\end{array}$ & $\begin{array}{l}\text { 법적 책임 } \\
\text { 성과 }\end{array}$ & $\begin{array}{l}\text { 윤리적 책임 } \\
\text { 성과 }\end{array}$ & $\begin{array}{l}\text { 기업 } \\
\text { 이미지 }\end{array}$ & $\begin{array}{l}\text { 기업 이미지 } \\
\text { 차이 검증 }\end{array}$ \\
\hline 경제적 책임(-) & 3.6176 & 4.3676 & 4.5515 & 4.0302 & \multirow{3}{*}{$\begin{array}{l}F=7.048 \\
(p=0.001)\end{array}$} \\
\hline 법적 책임(-) & 4.0000 & 2.8071 & 2.5000 & 3.1706 & \\
\hline 윤리적 책임(-) & 4.4531 & 3.1719 & 2.7031 & 3.6502 & \\
\hline
\end{tabular}

〈그림 3〉 CSR 차원별 부정적 메시지의 효과

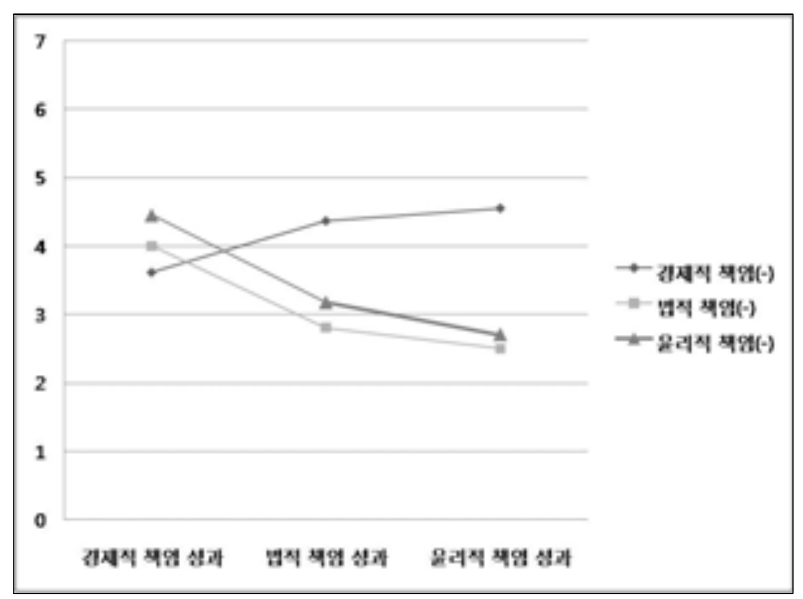


한 부정적 정보를 접한 집단의 경우, 법적 책임 (2.8071) =윤리적 책임(2.5000)<경제적 책임(4.000) 순으로, 윤리적 책임에 대한 부정적 정보를 접 한 집단의 경우, 법적 책임 $(3.1719)=$ 윤리적 책 임(2.7031)<경제적 책임(4.4531) 순으로 높게 나타났다. 이는 경제적 책임을 제외한 법적 책 임과 윤리적 책임 모두에서 역시 파급효과가 일어남을 알 수 있다.

이러한 파급효과로 인해 기업 이미지 평가 결 과에 차이가 있는지를 보기 위해 분산분석을 실시하였다. 그 결과 법적 책임을 접한 집단의 기업 이미지(3.1706)가 경제적 책임에 대한 부 정적인 정보를 접한 집단의 기업 이미지(4.0302) 보다 낮은 것으로 나타났다 $(\mathrm{F}=7.048, \mathrm{p}=0.001)$. 이는 법적 책임에 대한 부정적인 정보를 접한 집단에서 파급 효과가 일어나 기업 이미지에 대한 부정적인 이미지가 더 커졌음을 보여주는 결과이다.

이상의 결과를 볼 때, 소비자들이 $\mathrm{CSR}$ 차원 별 메시지를 접할 경우, 파급효과가 일어날 것 이라는 가설 1 과 부정성 효과로 인해 파급효과 가 더 커져 기업 이미지에도 영향을 미칠 것이 라는 가설 2 모두 지지되었음을 알 수 있다.

\section{IV. 결 론}

\section{1 연구의 의의 및 시사점}

기존의 많은 연구들은 $\mathrm{CSR}$ 이 기업의 성과에 미치는 다양한 긍정적인 결과와 더불어 부정적 인 메시지가 미치는 부정적인 영향에 대해 다
양한 연구들을 진행해 왔다. 기존 연구에 의하 면, $\mathrm{CSR}$ 에 대한 긍정적인 정보는 기업 이미지 를 비롯하여 제품 이미지, 브랜드 평가 등과 같 은 마케팅 변수와 더불어 주가나 투자 의도 등 과 같은 재무적인 성과에도 긍정적인 영향을 미치는 것으로 나타났다(Brown and Dacin 1997;

Freeman 1992; Folkes and Kamins 1999; Klein and Dawar 2004). 반면 부정적인 메시지는 아 무리 기업이 뛰어난 능력을 가지고 있다 하더 라고 소비자들의 구매 의혹을 저하시킬 뿐 아 니라 기업 전체적인 성과에 악영향을 미친다 (Sen and Bhattacharya 2001).

이러한 다양한 연구에도 불구하고 관련된 정 보들, 특히 $\mathrm{CSR}$ 차원별 정보들이 소비자의 기 업 이미지 평가에 영향을 미치는 메커니즘에 대한 연구는 부족한 실정이다. 기존의 몇몇 연 구들조차 $\mathrm{CSR}$ 을 단일 차원의 개념으로 측정함 으로써 정확한 $\mathrm{CSR}$ 차원별 정보의 효과를 보 여주는데 한계점을 지니고 있다. 본 연구는 이러한 한계점을 극복하기 위해 Schwartz and Carroll(2003)이 제시한 세 가지 차원을 기준으 로 차원별 긍정적 정보와 부정적 정보를 접한 집단들이 기업 이미지를 평가함에 있어 어떠한 차이를 보이는지 연구하였다.

연구 결과, 긍정적 메시지 형태일 경우 법적/ 윤리적 책임과 관련된 메시지의 경우 파급효과 는 일어나지만 기업 이미지에 차이를 줄 만큼 크게 일어나지는 않는 것으로 나타났다. 즉, 파 급효과로 인해, 법적 책임을 다하는 기업은 당 연히 윤리적 책임을 다하고 있을 것이라고 여 기며, 윤리적 책임을 다하는 기업 역시 법적 책 임을 훌륭히 수행하고 있을 것이라고 생각하는 것이다. 이는 동일한 비용을 들여 $\mathrm{CSR}$ 관련 메 
시지를 마케팅 커뮤니케이션 도구로 활용할 경 우, 법적 책임이나 윤리적 책임과 관련된 메시 지를 사용하는 것이 $\mathrm{CSR}$ 성과에 대한 평가를 향상시키는데 더 효과적임을 보여준다. 하지만 이렇게 향상된 CSR 성과 평과 결과가 기업 이 미지에 차이를 줄 만큼 크지는 않은 것으로 나 타났다.

반면, 부정적 메시지 형태일 경우, 법적 책임 이나 윤리적 책임에 대한 메시지가 경제적 책 임에 대한 메시지보다 기업 이미지에 대해 더 큰 영향을 미치는 것으로 나타났다. 즉, 법적 책임과 윤리적 책임에 대한 부정적인 메시지는 파급효과를 유발시키는데 반해, 경제적 책임에 대한 메시지는 파급효과를 일으키지 않고 경제 적 책임에 대한 평가만 악화시키는 것으로 나 타났다. 이처럼 파급 효과와 부정성 효과가 동 시에 발생할 경우, 긍정적인 메시지와는 달리 기업 이미지에도 더 크게 훼손시키는 것으로 나타났다. 그러므로 기업들은 $\mathrm{PR}$ 관리를 통해 호의적인 기업 이미지를 유지하기 위해서는 CSR 차원들 가운데 특히, 법적 책임이나 윤리적 책 임과 관련된 부정적 정보들이 시장에 유포되지 않도록 사전에 관리하는 것이 중요하다.

\section{2 연구의 한계점 및 향후 연구 방향}

본 연구는 몇 가지 한계점을 지니고 있다. 첫 째, 긍정적 메시지의 경우, 파급효과는 있지만 기업 이미지에 미치는 영향의 차이는 크지 않 은 것으로 나타났다. 이는 단순히 평균값만을 비교하여 파급효과를 설명하는데 한계가 있을 수 있음을 보여준다. 추후 연구에서는 좀 더 세 밀하고 정확한 측정과 분석이 필요할 것으로
생각된다. 또한 이러한 결과가 다른 기업의 성 과 변수에서도 동일하게 나타나는지를 확인하 기 위해 고객 충성도나 구매 의도, 제품 이미지 등과 같이 소비자의 태도를 반영할 수 있는 다 양한 변수를 사용하여 효과를 검증해 볼 필요 가 있을 것이다. 둘째, 본 연구에서는 '한국 건 설’이라는 가상의 기업을 설정하여 실험을 진행 하였다. 이러한 실험의 한계를 극복하기 위해 실제 기업을 대상으로 소비자들의 태도 변화를 확인해 봄으로써 연구 결과의 일반화 가능성을 높일 수 있을 것이다. 마지막으로 표본을 선정 함에 있어 수도권 대학생만을 대상으로 하였기 때문에 연구의 일반화를 제고하기 위해 다양한 집단을 대상으로 한 연구가 수행되어야 할 것 이다.

〈논문 접수일: 2009. 06. 08〉

〈게재 확정일: 2009. 12. 14〉

\section{참고문헌}

Ahluwalia, Rohini, H. Rao Unnava, and Robert E. Burnkrant(2001), “The Moderating Role of Commitment on the Spillover Effect of Marketing Communications" Journal of Marketing Research, 38(4), 458-470.

Anderson, James C and David W. Gerbing (1988), "Structural Equation Modeling in Practice: A Review and Recommended Two-Step Approach," Psychological Bulletin, 103(3), 411-423.

Aupperle, K. E, A. B. Carroll, and J. D. 
Hatfield(1985), “An Empirical Examination of the Relationship between Corporate Social Responsibility and Profitability," Academy of Management Journal, 28(2), 446463.

Barich, H. and P. Kotler(1991), "A Framework for Marketing Image Management," Sloan Management Review, 32(2), 94-104.

Becker-Olsen, Karen L., B. Andrew Cudmore, and Ronald Paul Hill(2005), "The Impact of Perceived Corporate Social Responsibility On Consumer Behavior," Journal of Business Research, 59(January), 46-53.

Bowen, H. R.(1953), Social responsibilities of the businessman, New York: Harper \& Row.

Brown, Tom J. and Peter A. Dacin(1997), "The Company and the Product: Corporate Associations and Consumer Product Responses," Journal of Marketing, 61(1), 68-84.

Carroll, A. B.(1979), "A Three-dimensional Conceptual Model of Corporate Social Performance," Academy of Management Review, 4, 497-505.

(1991), “The Pyramid of Corporate Social Responsibility: Toward the Moral Management of Organizational Stakeholders," Business Horizons, 34, 39-48.

Clarkson, M. B. E(1995), "A Stakeholder Framework for Analyzing and Evaluating Corporate Social Performance," Academic Management Review, 20(1), 92-117.

Dichter, Emest(1985), "What's in an Image",
The Journal of Consumer Marketing, 2(Winter), 75-81.

Fishbein, Martin and Icek Ajzen(1981), "Acceptance, Yielding, and Impact: Cognitive Processes in Persuasion," in Cognitive Responses in Persuasion, R.E. Petty, T.M. Ostrom, and T.C. Brock, eds. Hillsdale, NJ: Lawrence Erlbaum Associates.

Fiske, Susan T.(1980), “Attention and Weight in Person Perception: The Impact of $\mathrm{Ne}^{-}$ gative and Extreme Behavior," Journal of Personality and Social Psychology, 38(6), 889-906.

Folks, V. S. and M. A. Kamins(1999), "Effects of Information About Firms' Ethical and Unethical Actions on Consumers' Attitudes," Journal of Consumer Psychology, 8(3), 243-260.

Fornell, Claes and David F. Larcker(1981), "Evaluating Structural Equation Models with Unobservable Variables and Measurement Error," Journal of Marketing Research, 18(February), 39-50.

Fombrun, C. and M. Shanley(1990), "What's in a Name? Reputation Building and Corporate Strategy," Academy of Management Journal, 33(2), 233-58.

Freeman, R. E.(1991), Business Ethics: The State of The Art, New York: Oxford University Press.

Herr, Paul M., Frank R. Kardes, and John Kim (1991), "Effects of Word-of Mouth and Product-Attribute Information on Persuasion: 
An Accessibility-Diagnosticity Perspective," Journal of Consumer Research, 17(4), 454462.

Homer, P. M. and A. Batra(1994), "Attitudinal Effects of Character-based Versus Competencebased Negative Political Communications", Journal of Consumer Psychology, 3(2), $163-85$.

Ibrahim, N. and J. Angelidis(1995). "The Corporate Social Responsiveness Orientation of Board Members," Journal of Business Ethics, 14(5), 405-501.

Janakiraman, Narayan, Robert J. Meyer, Adrea C. Morales(2006), "Spillover Effects: How Consumers Respond to Un expected Changes in Price and Quality," Journal of Consumer Research, 33(3), 361-369.

Klein, Jill and Niraj Dawar (2004), "Corporate Social Responsibility and Consumers' Attributions and Brand Evaluations in a Product-Harm Crisis," International Journal of Research in Marketing, 21(3), 203-217. Kotler, Philip(1982), Marketing for Nonprofit Organizations, 2nd ed., NJ: Prentice-Hall. Maheswaran, Durairaj and Joan Meyers-Levy (1990), "The Influence of Message Framing and Issue Involvement," Journal of Marketing Research, 27(3), 361-367.

Maignan, Isabelle(2001), “Consumer' Perceptions of Corporate Social Responsibilities: A Cross-Cultural Comparison," Journal of $\mathrm{Bu}^{-}$ siness Ethics, 30(1), 57-72.

, and O. C. Ferrell(2000), "Measuring
Corporate Citizenship in Two Countries: The Case of the United States and France," Journal of Business Ethics, 23(3), 283-297. and (2004), "Corporate Social Responsibility and Marketing: An Integrative Framework," Journal of the Academy of Marketing Science, 32(1), 3-19. Nunnally, Jum C. (1978), Psychometric Theory, 2nd ed. NY: McGraw-Hill.

Pinkston, T. S. and A. B. Carroll(1996), "A Retrospective Examination of CSR Orientations. Have They Changed?, Journal of Business Ethics, 15(2), 199-206.

Prabu, David, Susan Kline and Yang Dai (2005), "Corporate Social Responsibility Practices, Corporate Identity and Purchase Intention: A Dual-process Model," Journal of Public Relations Research, 17(3), 291-313.

Schwartz, M. S. and A. B. Carroll(2003), "Corporate Social Responsibility: a Three Domain Approach," Business Ethics Quarterly, 13 (4), 503-530.

Sen, Sankar and C. B. Bhattacharya(2001), "Does Doing Good Always Lead to Doing Better? Consumer Reactions to Corporate Social Responsibility," Journal of Marketing Research, 38(May), 225-243.

Skowronski, John J. and Donal E. Carlston (1989), "Negativity and Extremity Biases in Impression Formation: A Review of Explanations," Psychological Bulletin, 105 (January), 131-142. 
Till, Brian D. and Nowak, L. I.(2000), "Toward Effective Use of Cause-related Marketing Alliances," Journal of Product and Brand Management, 9(7), 474-484.

Winters, L. C.(1986), "The Effects of Brand Advertising on Company Image: Implication for Corporate Advertising," Journal of Advertising Research, 26(4), 54-59.

Wood, D. J.(1991), "Corporate Social Performance Revisited," Academy of Management Review, 16, 691-718. 


\title{
The Effect of Corporate Social Responsibility on Corporate Image: The Role of Spillover Effect and Negativity Effect based on CSR dimensions
}

\author{
Kim, Seongjin* \\ Kim, Jongkeun**
}

\begin{abstract}
Previous researches have proven that corporate social responsibility(adhere CSR) is positively related to corporate performance. But Most of CSR related researches have several limitations. One of limitations is that those researches treated CSR as unidimensional construct. Almost researchers in the area of CSR concepts insisted that CSR is consist of multi dimensions. Carroll's four dimensions of CSR have been utilized by numerous academicians. Carroll asserted that CSR is composed of four dimensions: economic, legal, ethical, and philanthropic responsibility. But Carroll's dimensions were revised as three dimensions by Schwartz and Carroll, because ethical and philanthropic responsibility are not mutually exclusive. If CSR construct is composed of multiple dimensions, a message related to one of dimensions changes beliefs or evaluations about other dimensions that are not mentioned in the message. This phenomenon is called as "spillover effect". According to Ahluwalia, Unnava, and Burnkrant, negative information spills over to attributes that are associated with the target attributes but not mentioned in the message. Like this, this preponderant effect of negative information over positive information has been termed the "negativity effect". In this paper, authors try to prove the spillover effect and negativity effect among Schwartz and Carroll's three dimensions(economic, legal, and ethical responsibility) of CSR. The results of this study show that messages related to legal and ethical responsibility cause spillover effect and influence consumers' evaluation to other dimensions. Moreover, when negativity effect is added on spillover effect, spillover effect is more increased. It means that negative messages related to legal and ethical responsibility is more harmful to corporate image than negative message related to economic responsibility. The results of this study will help
\end{abstract}

\footnotetext{
* Ph. D. Candidate, Korea University Business School, Korea University

** Full-time Lecturer, Department of Business Administration, Seoul Women's University
} 
companies to manage corporate image using CSR messages as marketing communication tools. Companies should manage messages related to legal and ethical responsibility for more efficiently managing corporate image. Specially, because negative messages related to legal and ethical responsibility are more harmful to corporate image, companies must take care not to spread out negative message related to legal and ethical responsibility. Finally, we discuss the implications of the findings and limitations.

Key words: corporate social responsibility, corporate image, types of message, spillover effect, negativity effect 